\title{
Flavonoid distribution in Pyracantha coccinea plants at different growth phases
}

\author{
Gelsomina Fico ${ }^{\mathrm{a}}$, Anna R. Bilia ${ }^{\mathrm{b}}$, Ivano Morelli ${ }^{\mathrm{a}, *}$, Franca Tomè
}

${ }^{a}$ Dipartimento di Chimica Bioorganica e Biofarmacia, Università di Pisa, via Bonanno 33, 56126 Pisa, Italy

${ }^{\mathrm{b}}$ Dipartimento di Scienze Farmaceutiche, Università di Firenze, via Gino Capponi 9, 50121 Firenze, Italy

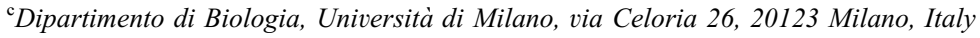

Received 30 July 1999; accepted 27 August 1999

\begin{abstract}
Flavonoid composition during the ontogenetic cycle was examined in Pyracantha coccinea. The flavonoid profiles of plants at different ages showed marked differences in aerial and hypogeal parts. In the vegetative phase there are flavonoids (flavanones, flavones, and flavonols) only in the aerial parts and they appear gradually during the plant life. These secondary metabolites are detectable in the roots exclusively in the reproductive phase. C 2000 Elsevier Science Ltd. All rights reserved.
\end{abstract}

Keywords: Pyracantha coccinea; Rosaceae; agazzino; Flavonoids; Ontogenetic cycle

\section{Introduction}

Pyracantha coccinea M.J. Roemer (Rosaceae) is an evergreen shrub found in Central and Southern Italy and also cultivated as an ornamental plant in Northern Italy (Pignatti, 1982).

It is used in traditional medicine for diuretic, cardiac and tonic properties in its fruits (Kowaleuki, Mrugasiewicz, 1971). Previous investigations showed, in the adult plants, the presence of flavonoids both in the aerial and in the hypogeal parts, although the qualitative compositions were very different (Bilia et al., 1991, 1993, 1994).

* Corresponding author. Fax $++39-050-43321$.

E-mail address: bioorg@farm.unipi.it (I. Morelli) 
We have carried out a study to see if the different flavonoid composition in hypogeal and aerial parts was acquired during the plant development or was present in every phase of plant growth. We have therefore examined $P$. coccinea at different growth phases (plantlets and plants in the vegetative, flowering and fruiting phases) and we report here the flavonoid pattern and its distribution in the plant organs.

\section{Materials and methods}

P. coccinea cultivated in Milano (Orto Botanico, Via Colombo), Italy, was employed in this study and a voucher specimen (P 101) was deposited in the herbarium of the Department of Biology of University of Milano.

The seeds were obtained from the same plants used for the previous investigation of the flavonoid content (Bilia et al., 1991, 1993).

The plants were grown initially in a greenhouse with a photoperiod of $12 \mathrm{~h}$, because the first phase of growth (from seeds to plantlets) is very delicate. Subsequently the plants were transferred to a field environment and harvested at four stages of development: 6 months ( $9 \mathrm{~cm}$ high), 1 year ( $25 \mathrm{~cm}$ high), 2 years ( $65 \mathrm{~cm}$ high), 3 years old $(80 \mathrm{~cm}$ high). After harvesting the plants were washed with water, powdered and extracted for flavonoid analysis.

The plant material: roots, stems, leaves, flowers, fruits, and seeds separately were exhaustively percolated with ethanol at room temp. for one week. The evaluation of the constituents was effected with TLC. Plates of silica gel and two solvent systems, $\mathrm{CHCl}_{3}-\mathrm{MeOH}(4: 1)$ and EtOAc- $\mathrm{HOAc}-\mathrm{HCO}_{2} \mathrm{H}-\mathrm{H}_{2} \mathrm{O}(11: 1.1: 1.1: 2.7)$ were used. The compounds were visualised by UV and spray reagents and identified by comparison with standard flavonoids. The spray reagents were diphenylborinic acid

Table 1

Flavonoids found in the aerial parts of Pyracantha coccinea, during the vegetative phase

\begin{tabular}{|c|c|c|c|c|}
\hline Flavonoids & Plantlets & 1 year old plants & 2 years & 3 years \\
\hline Apigenin & & & & + \\
\hline Eriodictyol & & & + & + \\
\hline Hexaacetilpyracanthoside & & & + & + \\
\hline Hyperoside & & + & + & + \\
\hline Isoorientin & & & + & + \\
\hline Isoquercitrin & & + & + & + \\
\hline Naringenin & & & & + \\
\hline Naringenin-7-glucoside & & & & + \\
\hline Pyracanthoside & + & + & + & + \\
\hline Quercetin & & & + & + \\
\hline Quercetin-3-rhamnoside & & & & + \\
\hline Rutin & + & + & + & + \\
\hline Vitexin & & & + & + \\
\hline Vitexin-2"-rhamnoside & & & & + \\
\hline
\end{tabular}


ethanolamine ester, called also Natural products reagent (NTS) and polyethylene glycol 4000 reagent (PEG); they were purchased from Aldrich-Chemie (Steinheim, Germany). For a complete identification of the constituents HPLC analysis was used and the $R_{\mathrm{t}}$ and UV spectra were compared with those of authentic samples.

The HPLC analyses were carried out in a Hewlett-Packard 1090 apparatus, with a diode-array detector. An RP-18 column was used (Merck $250 \times 4 \mathrm{~mm}$ ), flow rate of $1.3 \mathrm{ml} \times \min ^{-1}$ and the UV detector wave lengths were 256, 284, 350, $360 \mathrm{~nm}$. A gradient elution of $\mathrm{H}_{2} \mathrm{O}(\mathrm{A})$ at $\mathrm{pH} 3.5$ and $\mathrm{CH}_{3} \mathrm{CN}$ (B) was employed: $0-10 \min 88 \% \mathrm{~A}, 12 \% \mathrm{~B}$; $10-15 \min 82 \%$ A, $18 \%$ B; $15-30$ min $55 \%$ A, 45\% B; 30-35 min $100 \%$ B, 35-42 min $100 \% \mathrm{~B}$.

Table 2

Flavonoids found in Pyracantha coccinea during the reproductive phase

\begin{tabular}{|c|c|c|c|c|c|c|}
\hline Flavonoids & Roots & Stems & Leaves & Flowers & Fruits & Seeds \\
\hline Apigenin & & & + & & & \\
\hline Aromadendrin-5-me ether & + & & & & & \\
\hline Chrysin & + & & & & & \\
\hline Chrysin-5-glc & + & & & & & \\
\hline Dihydrokaempferol & + & & & & & \\
\hline Dihydrokaempferol-5-me ether & + & & & & & \\
\hline Dihydroquercetin & + & & & & & \\
\hline $2^{\prime} 4^{\prime}$-Dihydroxy-6'-methoxychalcone-4-glc & + & & & & & \\
\hline Dihydrowogonin & + & & & & & \\
\hline Dihydrowogonin-7-glc & + & & & & & \\
\hline \multicolumn{7}{|l|}{ Eriodictyol } \\
\hline Eriodictyol-7-glc-6"-Oac & & & + & & & \\
\hline Hexaacetylpyracanthoside & & & + & & & \\
\hline Hyperoside & & + & + & + & + & \\
\hline Isoorientin & & & + & & + & \\
\hline Isoquercitrin & & + & + & + & + & \\
\hline Kaempferol & & & + & & & \\
\hline Myricetin & & & + & & & \\
\hline Naringenin & + & & + & & & \\
\hline Norwogonin-5-glc & + & & & & & \\
\hline Pinocembrin & + & & & & & \\
\hline Pinostrobin-5-glc & + & & & & & \\
\hline Prunin & + & & + & & & \\
\hline Pyracanthoside & & + & + & + & + & \\
\hline Quercetin & & + & + & + & + & \\
\hline Quercetin-3-rut-7-glc & & & + & & + & \\
\hline Rutin & & + & + & + & + & \\
\hline Sakuranetin & + & & & & & \\
\hline Sakuranin & + & & & & & \\
\hline $5,7,2^{\prime}, 5^{\prime}$, -Tetrahydroxyflavanone & + & & & & & \\
\hline $5,7,2^{\prime}, 5^{\prime},-$ Tetrahydroxyflavanone-7-glc & + & & & & & \\
\hline Vitexin & & & + & & & \\
\hline Vitexin-2"-rha & & & + & & + & \\
\hline
\end{tabular}




\section{Results and discussion}

In the aerial parts, young plantlets showed the presence of pyracanthoside and rutin, while in one year old plants hyperoside and isoquercitrin were also found. The number of flavonoid compounds increased in the subsequent phases of growth. In the 2 years old plant, besides the above-mentioned compounds eriodictyol, quercetin, hexa-acetylpyracanthoside, isoorientin, quercetin-3-rhamnoside, and naringenin-7glucoside were present. In the 3 years old plants, apigenin, naringenin, vitexin, and vitexin-2"-rhamnoside were found (Table 1). During the vegetative phase flavonoids were not detected in the roots.

In the flowering and fruiting plants about 30 metabolites were found and these were also present in the roots (Table 2). Both flowers and fruits had a high content of flavonoids while, ripe seeds were totally devoid of these metabolites.

Pyracanthoside and rutin, the two flavonoids that appear firstly in the plantlets, are always present during the growth phases of $P$. coccinea and they are also the main constituents.

With regard to the distribution of flavonoids in the plants during the reproductive phase, it is noteworthy that flavanones and flavones, without or with only para oxygen substitution in the B ring, were present in the roots, together with a chalcone and three dihydroflavonols (Fig. 1). By contrast 5,7-dihydroxy flavonols and flavanones with mono-, di-, and tri-oxy substitution of the $\mathrm{B}$ ring were found in the aerial parts (Fig. 2). Furthermore, many flavonoids of the<smiles>[R1]Oc1cc(O)c2c(c1[R7])O[C@@H](c1ccc([R])cc1)CC2=O</smiles>

$\begin{array}{llll}\text { Pinocembrin } & R=R^{\prime}=R^{\prime \prime}=H & \text { Dihydrokaempferol } & R=R^{\prime}=R^{\prime \prime}=R^{\prime \prime}=H \\ \text { Naringenin } & R=O H, R^{\prime}, R^{\prime \prime}=H & \text { Dihydrokaempferol-5-me ether } & R=R^{\prime}=R^{\prime \prime}=H, R^{\prime \prime \prime}=C H_{3} \\ \text { Sakuranetin } & R=O H, R^{\prime}=H, R^{\prime \prime}=C_{3} & \text { Dihydroquercetin } & R=R^{\prime \prime}=R^{\prime \prime \prime}=H_{1}, R^{\prime}=O H \\ & & \text { Dihydrowogonin } & R=R^{\prime}=R^{\prime \prime \prime}=H, R^{\prime \prime}=O C H H_{3}\end{array}$<smiles>O=C1C[C@H](c2cc(O)ccc2O)Oc2cc(O)cc(O)c21</smiles>

$5,7,2^{\prime}, 5^{\prime}$-tetrahydroxy flavanone<smiles>COc1cc(O)cc(O)c1C(=O)/C=C/c1ccc(O)cc1</smiles>

2',4'-dihydroxy-6'-methoxycalchone<smiles>[R]c1c(O)cc(O)c2c(=O)cc(-c3ccccc3)oc12</smiles>

Chrysin Norwogonin
$\mathrm{R}=\mathrm{H}$ $\mathrm{R}=\mathrm{OH}$

Fig. 1. Aglycones in the ipogeal parts. 
Aglycones in the aerial parts<smiles>[R7]c1cc([C@@H]2CC(=O)c3c(O)cc(O)cc3O2)c([R])c([R])c1[R7]</smiles><smiles>O=c1cc(-c2ccc(O)cc2)oc2cc(O)cc(O)c12</smiles>

Apigenin<smiles>[R]c1cc(-c2oc3cc(O)cc(O)c3c(=O)c2O)cc([R])c1O</smiles>

Kaempferol $\quad \mathrm{R}=\mathrm{R}^{\prime}=\mathrm{H}$

$\begin{array}{ll}\text { Quercetin } & \mathrm{R}=\mathrm{R}, \mathrm{R}^{\prime}=\mathrm{OH}\end{array}$

Myricetin $\quad \mathrm{R}=\mathrm{R}^{\prime}=\mathrm{OH}$

Fig. 2. Aglycones in the aerial parts.

aerial parts had $O$ - and $C$-glycosilation with one or two sugar units (glucose, galactose, and/or rhamnose), while, in the roots only 5- or 7-O-monoglucosides were identified.

This spectrum of compounds does not allow taxonomic identification of the entity. However the study of the time course of flavonoid accumulation, during the plant life, shows that the capability of biosynthesising these metabolites appears gradually and in specific organs only. The peculiar distribution of flavonoid compounds in the roots and aerial parts poses an interesting problem with respect to the site of biosynthesis. Since there is evidence (Paré et al., 1992) that flavonoids with oxygen substitution and without oxygen substitution in the B ring are biosynthetized via two distinct biosynthetic pathways, we can presume that the first of these is activated in the aerial parts since the early phases of seeds germination and plantlet formation, while the onset of the second one occurs later, during the reproductive phase and only in the roots. Therefore the analysis of flavonoid composition during the ontogeny of $P$. coccinea can be useful tool in the study of the activation of secondary metabolism.

\section{Acknowledgements}

The authors thank Valerio Parravicini and Giovenale Giaccone (Orto Botanico, via Colombo 60, Universitá di Milano) for their contribution at the cultivation of P. coccinea. 


\section{References}

Bilia, A.R., Catalano, S., De Simone, F., Morelli, I., Pizza, C., 1991. An acetylated flavanone glucoside from leaves of Pyracantha coccinea. Phytochemistry 30, 3830-3831.

Bilia, A.R., Catalano, S., Pistelli, L., Morelli, I., 1993. Flavonoids from Pyracantha coccinea roots. Phytochemistry 33, 1449-1452.

Bilia, A.R., Morelli, I., Marsili, A., 1994. Two glicosides from Pyracantha coccinea roots: a new lignan and a new chalcone. Tetrahedron 50, 5181-5188.

Kowaleuki, Z., Mrugasiewicz, M., 1971. Neue flavanonheteroside in Crataegus phenophyrum. Planta Medica 19, 311-313.

Pare, P.W., Mischke, C.F., Edwards, R., Dixon, R.A., Norman, H.A., 1992. Induction of phenylpropanoid pathway enzymes in elicitor-treated cultures of Cephalocereus senilis. Phytochemistry 31, 149-153.

Pignatti, S., 1982. Flora d'Italia, Edagricole, Bologna, Italia, p. 610. 